\title{
Article 17. Monitoring the Utilization of Genetic Resources
}

1. To support compliance, each Party shall take measures, as appropriate, to monitor and to enhance transparency about the utilization of genetic resources. Such measures shall include:

(a) The designation of one or more checkpoints, as follows:

(i) Designated checkpoints would collect or receive, as appropriate, relevant information related to prior informed consent, to the source of the genetic resource, to the establishment of mutually agreed terms, and/or to the utilization of genetic resources, as appropriate;

(ii) Each Party shall, as appropriate and depending on the particular characteristics of a designated checkpoint, require users of genetic resources to provide the information specified in the above paragraph at a designated checkpoint. Each Party shall take appropriate, effective and proportionate measures to address situations of non-compliance;

(iii) Such information, including from internationally recognized certificates of compliance where they are available, will, without prejudice to the protection of confidential information, be provided to relevant national authorities, to the Party providing prior informed consent and to the Access and Benefit-sharing Clearing-House, as appropriate;

(iv) Checkpoints must be effective and should have functions relevant to implementation of this sub-paragraph (a). They should be relevant to the utilization of genetic resources, or to the collection of relevant information at, inter alia, any stage of research, development, innovation, pre-commercialization or commercialization.

(b) Encouraging users and providers of genetic resources to include provisions in mutually agreed terms to share information on the implementation of such terms, including through reporting requirements; and

(c) Encouraging the use of cost-effective communication tools and systems. 
2. A permit or its equivalent issued in accordance with Article 6, paragraph 3(e) and made available to the Access and Benefit-sharing Clearing-House, shall constitute an internationally recognized certificate of compliance.

3. An internationally recognized certificate of compliance shall serve as evidence that the genetic resource which it covers has been accessed in accordance with prior informed consent and that mutually agreed terms have been established, as required by the domestic access and benefit-sharing legislation or regulatory requirements of the Party providing prior informed consent.

4. The internationally recognized certificate of compliance shall contain the following minimum information when it is not confidential:
(a) Issuing authority;
(b) Date of issuance;
(c) The provider;
(d) Unique identifier of the certificate;
(e) The person or entity to whom prior informed consent was granted;
(f) Subject-matter or genetic resources covered by the certificate;
(g) Confirmation that mutually agreed terms were established;
(h) Confirmation that prior informed consent was obtained; and
(i) Commercial and/or non-commercial use.

\section{Overview}

Article 17 creates an obligation for each Party, particularly Parties with users in their jurisdiction, to take domestic measures to monitor and enhance transparency regarding the utilization of genetic resources, ${ }^{1}$ as a way to support other provisions related to compliance in the Protocol. ${ }^{2}$ The obligation mainly singles out two means of implementation: the establishment of checkpoints and the issuance of internationally recognized certificates of compliance. Checkpoints were one of the most contentious items in the negotiations of the Protocol, which may explain the unfortunate and convoluted drafting of Article 17(1), mainly due to political sensitivities concerning the linkages to the

1 Nagoya Protocol Article 17(1).

2 Nagoya Protocol Articles 14-16 and 18. 
IPR system. ${ }^{3}$ Article 17(2-4) focuses on the internationally recognized certificate of compliance: ${ }^{4}$ a conceptually complex tool that serves as evidence in a transnational context of the granting of PIC and establishment of MAT.

To fully appreciate the relevance of Article 17 in the international ABs regime created by the Protocol, it should be recalled that the СвD is silent on specific measures to monitor the utilization of genetic resources and the implementation of related benefit-sharing obligations. Some commentators have argued that the $\mathrm{CBD}^{5}$ contains an obligation of result to share benefits arising from research and development in a fair and equitable way, and the need for monitoring measures is a logical consequence of functional ABs frameworks. ${ }^{6}$ The Bonn Guidelines paid little attention to monitoring measures, although they included some reference to national monitoring and reporting, ${ }^{7}$ as well as to means for verification. ${ }^{8}$ State practice so far has been limited in implementing user measures in general, let alone in providing for systematic monitoring for the purpose of ABs. ${ }^{9}$ Against this background, the role of Article 17 is to complement the general obligations for Parties to provide for users' compliance with domestic ABs frameworks ${ }^{10}$ and facilitate compliance with MAT. ${ }^{11}$ To that end, Article 17 contains more detailed obligations focusing on 'concrete tools'12 for monitoring uses and/or users of genetic resources to detect possible instances of users' violations of domestic ABs measures.

3 Pavoni, "Nagoya Protocol and wTo Law," op. cit., 200-205, particularly 203-204, and 213.

4 Brendan Tobin, Geoff Burton and José C. Fernandez-Ugalde, Certificates of Clarity or Confusion: The Search for a Practical, Feasible and Cost Effective System for Certifying Compliance with PIC and MAT (Yokohama: UNU-IAS, 2008), accessed 30 November 2013, $<$ http://collection.unu-mc.org/view/UnU:3123>.

5 свD Article 15(7) first sentence.

6 E.g., Tvedt and Young, Beyond Access, op. cit., 40.

7 Bonn Guidelines, paragraphs 55-56.

8 Bonn Guidelines, paragraphs 57-58.

9 Brendan Tobin, Sam Johnston and Charles V. Barber, Options for Developing Measures in User Countries to Implement the Access and Benefit-Sharing Provisions of the Convention on Biological Diversity (Yokohama: UnU-IAS, 2003), accessed 30 November 2013, $<$ http://unu.edu/publications/policy-briefs/options-for-developing-measures-in-usercountries-to-implement-the-access-and-benefit-sharing-provisions-of-the-conventionon-biological-diversity-2nd-edition.html>; Morgera, Buck and Tsioumani, "Conclusions," op. cit., 515; Tvedt and Fauchald, "Implementing the Nagoya Protocol on ABs," op. cit., 383-402.

$10 \quad$ Nagoya Protocol Articles 15-16.

11 Nagoya Protocol Article 18.

12 Glowka and Normand, "Nagoya Protocol on Access and Benefit-sharing," op. cit., 37. 
Article 17 also includes other mandatory means of implementation (as part of a non-exhaustive list), such as an obligation to 'encourage' (i.e. at least to remove barriers to, and/or create incentives for $)^{13}$ users and providers to include in MAT provisions on reporting and information-sharing, ${ }^{14}$ and all ABS stakeholders to use cost-effective communication tools. ${ }^{15}$ As to the latter, Parties may consider encouraging users to participate in existing initiatives, ${ }^{16}$ such as IT-based communication tools for exchanging information on genetic resources. ${ }^{17}$ The following sections will focus on the more complex interpretative questions raised by the provisions on checkpoints and the internationally recognized certificate of compliance, in turn.

\section{2}

\section{Checkpoints}

Checkpoints under the Protocol have the responsibility to monitor the utilization ${ }^{18}$ of genetic resources, in order to support the possible detection of user's violations of domestic ABs frameworks in other countries. It remains to be seen whether Parties may empower checkpoints to also check breaches of MAT, although the Protocol does not require checking their content but only their formal establishment. ${ }^{19}$ On the other hand, domestic ABs frameworks may provide for specific requirements on the substantive content of $\mathrm{MAT}^{20}$

13 On the obligation to encourage, see this commentary on Article 9, section 1.

14 Nagoya Protocol Article 17(1)(b). See also Article 6(3)(g) and this commentary on Article 6, section 7. It may be usefully recalled that Parties will be well advised to effectively encourage such inclusion in MAT, which are more easily enforced than PIC in a transnational context, as discussed in this commentary on Article 18, section 5 .

15 Nagoya Protocol Article 17(1)(c).

16 For example, the EU draft regulation would encourage users' associations to seek recognition of a combination of procedures, tools or mechanisms (e.g., on the deployment of data-sharing tools for tracking) developed for the purpose of implementing their obligations under the regulation as 'best practice', by subjecting users implementing such recognized best practice to less intense compliance checks (see draft articles 8-9).

17 One example can be found in the microbial sector, where efforts are undertaken to integrate all known equivalent strain numbers and corresponding information into a single strain passport page: "StrainInfo," University of Gent et al., accessed on 7 February 2014, <www.straininfo.net/>.

18 Nagoya Protocol Article 2(c). See this commentary on Article 2, section 2.

19 Article 17(1)(a)(i).

20 As the list of minimum requirements for MAT to be established in domestic ABS frameworks at Article 6(3)(g) is non-exhaustive: see this commentary on Article 6, section 7 . 
and Parties can therefore require their checkpoints to carry out monitoring tasks also in that regard, particularly if these requirements are well publicized. The designation of checkpoints needs to be backed up by domestic measures to obtain from users relevant information. ${ }^{21}$ This is coupled with an obligation for each Party to take measures to address situations of non-compliance by users with requirements to provide relevant information. ${ }^{22}$

During the negotiations, developing countries argued for the obligatory establishment of predetermined checkpoints, particularly at patent offices, so that users seeking IPRS on inventions using genetic resources would be obliged to disclose information on PIC and MAT. This was based on the understanding that IPRs are usually sought at an early stage of the research and development, and/or commercialization, process with a view to securing monetary benefits from the utilization of genetic resources. Industrialized countries, on the other hand, argued against creating unduly burdensome procedures at the national level in relation to IPRs, ${ }^{23}$ and expressed concerns about flexibility and costeffectiveness. ${ }^{24}$ Certain developed countries explicitly opposed any mandatory requirement for disclosure of ABS-related information in IPR applications and an obligation to designate patent offices as checkpoints, in line with their position in the WTO TRIPS negotiations. ${ }^{25}$ The question of how to establish mechanisms or obligations that can capture genetic resources-related benefits from the IPR systems and channel them back to the country providing genetic resources and/or traditional knowledge ${ }^{26}$ remains open in various fora. ${ }^{27}$

21 Nagoya Protocol Article 17(1)(a)(ii), first sentence.

22 Nagoya Protocol Article 17(1)(a)(ii), second sentence. This provision can be read together with Parties' obligations to establish appropriate, effective and proportionate measures to address situations of non-compliance, which is provided for in Nagoya Protocol Article 15.

23 Singh Nijar, "An Asian Developing Country's View," op. cit., 252-254.

24 Buck and Hamilton, "Nagoya Protocol," op. cit., 53. These concerns were related to the expectation that Parties with users within their jurisdiction would need to carry out inspections of private research facilities and laboratories in their territory and determine the source of 'all biological material involved in such utilization' in order to effectively monitor users within their jurisdiction: Young, "An International Cooperation Perspective," op. cit., 476.

25 A number of developed countries oppose amendment of Article 27(3)(b) of the TRIPS Agreement to introduce a mandatory disclosure requirement: see Morgera and Tsioumani, "Evolution of Benefit-Sharing", op. cit., 168-169; and Pavoni, "Nagoya Protocol and wTo Law," op. cit., 208-212.

26 The omission of traditional knowledge from Nagoya Protocol Article 17 is discussed in this commentary on Article 16, section 3.

27 See Introduction to this commentary, section I.1. Andersen et al., International Agreements and Processes, op. cit., 34. Note also Oldham and Burton, "Defusing Disclosure in Patent 
As a result, Article 17(1) places an obligation on each Party (whether it characterizes itself mainly as provider or as user of genetic resources) to designate one or more checkpoints to gather/receive information on the utilization of genetic resources. In other words, the Protocol requires Parties to designate at least one checkpoint, but leaves them flexibility in deciding which national entity will play that role. So, nothing in the Protocol prevents Parties from designating patent offices as checkpoints. It has been argued however that, in the absence of a 'clear mandate and authoritative guidance from the Protocol' in that regard, Parties' domestic rules designating patent offices as checkpoints may arguably be considered in tension with WTO law. ${ }^{28}$

Parties may as well decide to designate other entities as checkpoints, including competent national authorities, ${ }^{29}$ other authorities providing regulatory or marketing approval of products, customs officers, ${ }^{30}$ and/or research funding institutions. ${ }^{31}$ The flexibility left by Article 17 is such that Parties may also decide to provide government incentives for user self-monitoring and for otherwise creating transparency in the chain of users (for instance, through independent third-party monitoring such as certification), ${ }^{32}$ and also designate

Applications," op. cit., who argue that as a result of unilateral action on disclosure in patent applications in major national product markets, no significant genetic resourcebased product can be launched internationally without disclosure having taken place in several key markets.

28 Pavoni, "Nagoya Protocol and wTo Law," op. cit., 204. Note also conceptual and practical difficulties in utilising the patent system for enforcement of ABs laws discussed by Young, "An International Cooperation Perspective," op. cit., 478-479. Such difficulties include the imposition of significant costs on providers challenging a patent and the fact that the patent offices are 'strongly skewed in favour of patent issuance' because they are funded by patent application fees (ibid., 479).

29 See lack of Protocol indications on role of competent national authorities in user countries: this commentary on Article 13, section 3. See also EU draft regulation, draft article $7(2)$.

30 This could arguably include also the Convention on International Trade in Endangered Species of Wild Fauna and Flora (Washington DC, 3 March 1973, in force 1 July 1975) 993 UnTs 243 (CITES) enforcement officers: on the difficulties in combining systems of enforcement under the two multilateral environmental treaties, see Young, "An International Cooperation Perspective," op. cit., 479-481.

31 Some of these options were outlined in the Nagoya Draft, draft article 13(1)(a). For a brief discussion in the European region and in Latin America, see Lago Candeira and Silvestri, "Challenges in the Implementation of the Nagoya Protocol," op. cit., 279-280 and 291; and Cabrera Medaglia, "Implementation of the Nagoya Protocol," op. cit., 362-363.

32 Note that certification was one of the means to support compliance suggested in the Bonn Guidelines, paragraph 16(d)(v). On the likely shortfalls of certification in the ABS context, see Young, "An International Cooperation Perspective," op. cit., 481-482. 
non-government entities as checkpoints, such as researchers in receipt of public funding and genebanks. ${ }^{33}$ It remains to be seen, however, whether these non-government checkpoints would ensure monitoring of the entirety of ABS transactions in a given country, and could be considered 'effective' to perform all the functions foreseen in Article 17 and ultimately contribute to the realization of the objectives of the Protocol on fair and equitable benefit-sharing. ${ }^{34}$

\subsection{Characteristics and Functions}

Designated checkpoints must meet all of the cumulative criteria concerning their characteristics and functions set out in Article 17(1)(a). First of all, designated checkpoints must either actively gather ('collect') or at least be the recipients ('receive') of information on PIC, the source ${ }^{35}$ of the genetic resource, the establishment of MAT, and/or the utilization of genetic resources. ${ }^{36}$ It may be argued that tasking checkpoints with active duties in this regard may facilitate the detection of cases of misappropriation. Article 17(1)(a) leaves Parties discretion as to whether to task checkpoint(s) to take both an active and a passive role, and whether to extend their duties to utilization. The qualification 'as appropriate' points to different tasks depending on the different types of checkpoints that will be designated. The reference to 'and/or' at the end of the list of types of information to be collected/received, read together with the qualification 'as appropriate', suggests that designated checkpoints will need to collect one, more or all of the types of information listed.

Second, checkpoints are mandated ${ }^{37}$ to provide relevant information to relevant national authorities (including competent national authorities), ${ }^{38}$ the Party providing PIC, and to the ABs Clearinghouse, ${ }^{39}$ as appropriate. Information to be channeled by checkpoints may also include information from the internationally recognized certificates of compliance 'where they are available.' The latter expression points to instances in which the genetic

33 Glowka and Normand, "Nagoya Protocol on Access and Benefit-sharing," op. cit., 39.

34 See this commentary on Article 1.

35 This was inserted to achieve consistency with some pending proposal on the disclosure of origin or source in the WTO/TRIPS negotiation. Reference to 'source' might be quite useful in case in which users obtained genetic resources from a country that is not the country of origin: Tobin, Johnston and Barber, Options for Developing Measures, op. cit.

36 Nagoya Protocol Article 17(1)(a)(i). See Article 2(c) and this commentary on Article 2, section 2.

37 Nagoya Protocol Article 17(1)(a) (iii), although the wording relies on a passive formulation that may engender some uncertainty in that regard.

38 Nagoya Protocol Article 13(2). See this commentary on Article 13, section 3.

39 Nagoya Protocol Article 14. 
resources utilized are considered outside the scope of the Nagoya Protocol, ${ }^{40}$ countries do not require $\mathrm{PIC}^{41}$ or do not require issuance of certificates of compliance, ${ }^{42}$ or may have taken into account in different ways the 'special considerations' identified in the Protocol. ${ }^{43}$ The qualification of the mandate for checkpoints to channel relevant information 'without prejudice to the protection of confidential information' points to unresolved legal questions regarding confidentiality that still need to be clarified under the Protocol. ${ }^{44}$

Third, designated checkpoints must be 'effective. ${ }^{45}$ Such effectiveness refers to the actual capabilities of designated checkpoints to ensure monitoring and enhanced transparency in the utilization of genetic resources, and ultimately contribute to realizing the objective of the Protocol. ${ }^{46}$ Effectiveness is therefore the yardstick to evaluate whether Parties comply with Article 17, including by the compliance procedures and mechanisms to be established under the Protocol. ${ }^{47}$ Effectiveness of designated checkpoints in a user country may also be used as a criterion for evaluating individual applications for access to genetic resources, if so determined by provider countries' national access measures. ${ }^{48}$

Fourth, checkpoints' functions as spelt out in domestic measures should effectively contribute to gathering or at least receiving relevant information, as well as channeling it appropriately (domestically or externally). The provision, however, leaves discretion to Parties in determining whether designated checkpoints will monitor the whole of the research-development value chain, or just some of its stages ('at, inter alia, any stage'). ${ }^{49}$ So, it remains to be determined on a case-by-case basis whether in countries where checkpoints(s) collect information only at the very early stages of the research and development process, such checkpoints can be considered effective in achieving the objective of Article 17 and ultimately the objective of the Protocol.

Finally, it remains to be seen whether countries implementing Article 17 will empower checkpoints to track genetic resources from the stage of research to the stage of commercialization. The Protocol negotiators considered, and

$40 \quad$ See this commentary on Article 3, section 3.

41 Nagoya Protocol Article 6(1). See this commentary on Article 6, section 3.

42 See section 3 below.

43 Nagoya Protocol Article 8.

44 Nagoya Protocol Article 14(2). These questions are discussed in this commentary on Article 14, section 5.

45 Beginning of Nagoya Protocol Article 17(1)(a)(iv).

46 See this commentary on Article 1.

47 See this commentary on Article 30.

48 Nagoya Protocol Article 6(3)(b) and this commentary on Article 6, section 5.2.

49 Nagoya Protocol Article 17(1)(a)(iv). 
eventually decided against, a substantive obligation for Parties to 'track' genetic resources at all stages of the user chain through a range of specific measures, including a unique identifier for genetic resources, for gathering the information needed to establish whether a user is in compliance or not. ${ }^{50} \mathrm{In}$ the absence of such a provision, there is no basis in the Protocol for setting up a multilateral framework supporting coordinated efforts to track the flow of genetic resources across jurisdictions. ${ }^{51}$ The Protocol, however, does not prevent Parties to mandate their checkpoints to track genetic resources from the stage of research to the stage of commercialization through measures that do not require collaboration from other Parties, or possibly by joining efforts with other willing Parties through bilateral or regional agreements. ${ }^{52}$

\section{The Internationally Recognized Certificate of Compliance}

Article 17(2-4) concerns the internationally recognized certificate of compliance as a tool to facilitate acceptance of evidence of compliance with the provider countries' domestic ABs frameworks in a transnational context. ${ }^{53}$ Article 17(2) establishes that certificates are created by making available permits

5o A proposal by the African Group, for example, would have obliged Parties to 'facilitate an efficient, easy to use certification process through the use of new technology which may include: (i) Cost efficient publicly searchable certificate databases providing evidence of PIC and MAT, (ii) Recording of progressive compliance on such databases as conditions of PIC and MAT are met, (iii) Searchable patent application and registration databases, (iv) Integration of genomic and morphological taxonomy to create species certainty, (v) Low cost, portable, gene based bar-coding technology to create rapid attack taxonomy, (vi) Linking unique identifiers to gene based bar-coding.' свр Working Group on ABs, "Collation of operative text submitted," unep/cbD/WG-ABs/7/4, 28-29. See also draft article 13 in the Nagoya Draft, which was titled 'MONITORING[, TRACKING] AND REPORTING THE [UTILIZATION] OF GENETIC RESOURCES [AND ASSOCIATED TRADITIONAL KNOWLEDGE]' (brackets in the original).

$5^{1}$ The technical challenges and opportunities related to monitoring and tracking the flow of genetic resources are succinctly described by George M. Garrity et al., "Studies on Monitoring and Tracking Genetic Resources" (2 March 2009) un Doc Unep/CbD/ WG-ABS/7/INF/2.

52 See this commentary on Article 4, section 3.

53 Nagoya Protocol Article 17(3). On possible wTo law implications of the internationally recognized certificate of compliance, see Tobin, Johnston and Barber, Options for Developing Measures, op. cit., 197-199. 
or their equivalent ${ }^{54}$ to the ABs Clearinghouse. ${ }^{55}$ The wording of Article 17(2) does not specify who has the responsibility to make available a domestic permit to the international ABS Clearinghouse (as it is formulated in the passive form), although elsewhere in the Protocol this appears to be the responsibility of provider countries. ${ }^{56}$ This is compounded by the Protocol's silence as to whether national competent authorities are the ones obliged to make the permits available to the ABs Clearinghouse. ${ }^{57}$ More importantly, Article 17(2) does not specify whether all permits (as it mentions 'a permit') should be made available, with a view to elevating them to the status of internationally recognized certificate of compliance. This interpretative uncertainty also arises from a combined reading of the other Protocol provision requiring 'notify[ing $]^{158}$ the ABs Clearinghouse of the issuance of a permit (rather than 'submitting' the permit), and the fact that the explicit requirement to submit the permit to the ABs Clearinghouse is expressed in the passive form elsewhere in the Protocol. ${ }^{59}$ Because of these textual inconsistencies, some commentators have argued that the certificate is not mandatory. ${ }^{60}$ However, Parties would be well advised to clarify (either multilaterally through the Protocol's governing body ${ }^{61}$ or unilaterally through their domestic ABs frameworks) whether there is a mandatory requirement for permits to be elevated to internationally recognized certificates of compliance, with a view to promoting legal certainty. ${ }^{62}$ A mandatory certificate could in particular minimize room for uncertainty for user countries implementing their obligations to monitor and provide for compliance under the Protocol.

Article 17(3) clarifies that the legal effect of the certificate is to oblige Parties to consider it acceptable evidence under their national legal systems that the genetic resource covered has been accessed in accordance with PIC and that

54 Issued under Nagoya Protocol Article 6(3)(e). The meaning of the term 'its equivalent' is explained in this commentary on Article 14, section 4.

55 Nagoya Protocol Article 14.

56 Nagoya Protocol Article 6(3) refers to 'each Party requiring PIC'.

57 Nagoya Protocol Article 13(2).

58 Nagoya Protocol Article 6(3)(e).

59 Nagoya Protocol Article 14(2)(c).

6o Glowka and Normand, "Nagoya Protocol on Access and Benefit-sharing," op. cit., 37 (who refer to the 'possibility to elevate a permit ... to the status of an internationally recognized certificate of compliance' - emphasis added). See also countries arguing for voluntary certification during the Protocol negotiations: Singh Nijar and Pei Fern, Nagoya ABS Protocol, op. cit., 279-350.

61 Nagoya Protocol Article 26(4)(a); see this commentary on Article 26, section 2.

$62 \quad$ Nagoya Protocol 9th preambular paragraph. 
MAT were established according to another country's domestic ABs framework. Ultimately, therefore, the certificate may assist users in fending off allegations of misappropriation.

Article 17(4) lists minimum information (of a procedural nature) that must be contained in the certificate. ${ }^{63}$ If a permit is made available to the ABS Clearinghouse without containing all the required information, it may arguably not be considered an internationally recognized certificate of compliance, ${ }^{64}$ although it remains unclear who will verify that all required information has been submitted. ${ }^{65}$ The Protocol allows Parties to add to the list of mandatory information in their domestic ABs frameworks. Article 17(4) once again draws attention to issues of confidentiality, which however still need to be clarified under the Protocol. 66

The 'unique identifier of the certificate' is intended to minimize efforts by users and public administrators carrying out computer-based searches of certificates; ${ }^{67}$ it would basically allow for searches based on a 'registration number' allocated to each certificate. It may be particularly useful to identify permits that have been modified or updated, ${ }^{68}$ as their successive iterations should have the same identifier in common. It should thus not be confused with the proposed unique identifier of genetic resources as part of a multilateral tracking system that was not included in the Protocol. ${ }^{69}$ Parties could still decide to explore opportunities resulting from advances in identifying a

63 Nagoya Protocol Article 17(4) also determines the information that needs to be made available on a permit to the ABS Clearinghouse. Contingent on the interpretation of Nagoya Protocol Article 17(2), this list will either result in a minimum harmonization of domestic permits and their equivalents, or it could be implemented by providing a common format for registering information on domestic permits or equivalents in the ABs Clearinghouse. See this commentary on Article 14, section 4.

64 Glowka and Normand, "Nagoya Protocol on Access and Benefit-sharing," op. cit., 37.

65 See this commentary on Article 14, section 4.

66 Nagoya Protocol Article 14(2). See this commentary on Article 14, section 5.

67 Greiber et al, Explanatory Guide, op. cit., 181.

68 As discussed in this commentary on Article 14, section 4.

69 See section 2 above. Note that unique identifiers of living modified organisms are used to satisfy the documentation requirements of the Cartagena Protocol on Biosafety: the OECD Unique Identifiers of Transgenic Plants are alphanumeric codes given to each living modified organism approved for commercial use, a registry of which is maintained on the Biosafety Clearinghouse: "LMO Registry," CBD, accessed 19 February 2014, <http://bch .cbd.int/database/lmo-registry $>$. This registry provides summary information on all living modified organisms registered in the Biosafety Clearinghouse including transformation events and genetic modifications, as well as links to all relevant decisions and risk assessment reports. 
genetic resource ${ }^{70}$ to further develop the internationally recognized certificate of compliance, by including in the information contained in certificates available unique identifiers for genetic resources in the future.

On a final, substantive note, the purely procedural reference to the 'confirmation that MAт were established' in Article 17(4) confirms that the Protocol does not provide for any mechanism to check compliance vis-à-vis the content of мAт. ${ }^{71}$ This also means that the Protocol does not contain any international mechanism for assessing the fairness and equity of benefit-sharing requirements in specific ABs transactions. ${ }^{72}$

\footnotetext{
70 Garrity et al., "Studies on Monitoring and Tracking", op. cit., 29-85.

71 See also section 2 above.

72 See this commentary on Article 6, section 2 and conclusions to this commentary, section 2 , where the critical relevance of MAT for ensuring fairness and equity of benefit-sharing is discussed.
} 